\title{
Family history of colorectal tumours and implications for the adenoma-carcinoma sequence: a case control study
}

\author{
M-C Boutron, J Faivre, V Quipourt, P Senesse, C Michiels
}

\begin{abstract}
Family history of colorectal cancer is a risk factor for sporadic colorectal cancer, but it is not known which step of the adenomacarcinoma pathway it influences. This case control study investigated the relation between family history of cancer and colorectal adenomas and cancers. Family history of colorectal cancer (FHCRC) was as frequent in small $(<10 \mathrm{~mm})$ adenoma patients $(11 \cdot 7 \%, n=154)$ as in polyp free patients $(10.6 \%, n=426)$, whereas it was more frequent in patients with large adenoma(s) $\quad(18 \cdot 8 \%, \quad n=208 ; \quad p<0 \cdot 01)$. Odds ratios for FHCRC were $1 \cdot 2(p>0 \cdot 10)$ for small adenomas and $2 \cdot 1(p<0 \cdot 01)$ for large adenomas. Family history of other (non-colorectal) cancers (FHOC) was similar in the three groups. Patients with a colorectal cancer $(n=171)$ had more frequently a family history of cancer, both colorectal $(15.8 \% ; p<0.01)$ and other cancers $(35.7 \% ; \mathbf{p}<0.001)$ than general population controls $(n=309$; FHCRC: 8.1\%; FHOC: $21 \cdot 7 \%$ ). In a logistic model, both factors were independently related to colorectal cancers (odds ratios: 1.9 $(p<0.05)$ for FHCRC and $2 \cdot 1(p<0 \cdot 001)$ for FHOC). These data suggest that family history of colorectal cancer influences only the growth of adenomas or their malignant transformation. The finding of a further predisposition to any type of cancer needs to be confirmed.

(Gut 1995; 37: 830-834)
\end{abstract}

Keywords: colorectal cancer, family history, adenomacarcinoma pathway.

Family history of colorectal cancer (FHCRC) is recognised as a risk factor for sporadic colorectal tumours, although the genetic background is not as important for these tumours as it is for familial polyposis coli or for hereditary non-polyposis colorectal tumours. Considerable progress has been achieved recently in the field of molecular genetics for hereditary colorectal cancers: the cloning of the APC gene for familial polyposis coli, ${ }^{1}$ and the discovery of genes controlling for replication errors, $\mathrm{hMSH} 2^{2}$ and $\mathrm{hMLH} 1,{ }^{3}$ involved in hereditary non-polyposis colorectal tumours. These findings have helped in the understanding of molecular events during the progression from normal mucosa to sporadic colorectal cancer ${ }^{4}$ but the gene(s) involved in the predisposition to sporadic colorectal cancers have not yet been discovered. These cancers are considered to be in most cases the result of a multistep process, adenoma formation, adenoma growth, and malignant transformation. A pedigree analysis in Utah suggested that common adenomas are inherited and that a partly penetrant autosomal dominant gene would explain the familial occurrence. ${ }^{56}$ To date, it is not known precisely which step(s) of the adenoma-carcinoma sequence are influenced by a family history of cancer. Therefore, we studied the family history of cancers in first degree relatives of subjects with small adenomas ( $<10 \mathrm{~mm}$ in diameter), large adenomas, or cancers of the large bowel, and in population based, as well as in polyp free, controls.

\section{Patients and methods}

A case control study was set up in the Côte d'Or area (Burgundy, France), to investigate environmental and familial risk factors in relation to the colorectal adenoma-carcinoma sequence. Details of the study population and design have been presented elsewhere. ${ }^{7}$ Briefly, patients eligible for the study were residents of the Côte d'Or area, aged 30 to 79 . Exclusion criteria were familial polyposis coli, hereditary non-polyposis colorectal cancer or an inflammatory bowel disease. Table I gives the sex, age, and distribution of the study groups. Between April 1985 and April 1990, 171 patients with a histologically confirmed colon or rectal carcinoma were recruited from all gastroenterologists (public and private practices) of the Côte d'Or area, as were 208 patients with at least one adenoma $10 \mathrm{~mm}$ or more in diameter, 154 patients with only small adenomas $(<10 \mathrm{~mm})$, and 426 polyp free controls (no adenoma, no hyperplastic polyp). Whereas the age distribution was rather similar in the two adenoma groups, for both sexes, polyp free controls were significantly younger. An additional control group $(n=309)$ was obtained from the general population census list, with sex and age distributions similar to the cancer cases to compare with the cancer group. The sample had been stratified by age and sex to conform to the theoretical distribution of colorectal cancers in the area. The stratification was more efficient in men than in women, where controls tended to be younger than cancer cases. Refusal rates were higher among population controls $(46.5 \%)$ than in the other groups, respectively $20 \cdot 1$ for the cancer group, 14.0 for the large polyp group, 20.2 for the small polyp group, and 22.0 for the polyp free controls.
Correspondence to: Dr M-C Boutron, UNITE 290, Hôpital Saint-Lazare, 75010 Paris, France.

Accepted for publication 31 May 1995 
TABLE I Distribution of the study groups by age and sex

\begin{tabular}{|c|c|c|c|c|c|c|c|}
\hline \multirow[b]{2}{*}{ Study group } & \multirow[b]{2}{*}{ Sex } & \multirow[b]{2}{*}{ No } & \multicolumn{4}{|c|}{ Age groups (\%) } & \multirow[b]{2}{*}{$\chi^{2}$ test } \\
\hline & & & $<50$ & $50-59$ & $60-69$ & $\geqslant 70$ & \\
\hline $\begin{array}{l}\text { Polyp free controls } \\
\text { Small adenomas } \\
\text { Large adenomas }\end{array}$ & $\begin{array}{l}M \\
M \\
M\end{array}$ & $\begin{array}{r}181 \\
85 \\
129\end{array}$ & $\begin{array}{l}37 \cdot 7 \\
17 \cdot 6 \\
13 \cdot 2\end{array}$ & $\begin{array}{l}24 \cdot 3 \\
27 \cdot 1 \\
27 \cdot 9\end{array}$ & $\begin{array}{l}22 \cdot 1 \\
35 \cdot 3 \\
41 \cdot 9\end{array}$ & $\begin{array}{l}16 \cdot 0 \\
20 \cdot 0 \\
17 \cdot 1\end{array}$ & $\mathrm{p}<0.001$ \\
\hline $\begin{array}{l}\text { Population controls } \\
\text { Cancer }\end{array}$ & $\begin{array}{l}M \\
M\end{array}$ & $\begin{array}{l}159 \\
109\end{array}$ & $\begin{array}{r}15 \cdot 7 \\
4 \cdot 6\end{array}$ & $\begin{array}{l}17 \cdot 6 \\
16 \cdot 5\end{array}$ & $\begin{array}{l}32 \cdot 1 \\
44 \cdot 0\end{array}$ & $\begin{array}{l}34 \cdot 6 \\
34 \cdot 9\end{array}$ & $\mathrm{p}>0 \cdot 10$ \\
\hline $\begin{array}{l}\text { Polyp free controls } \\
\text { Small adenomas } \\
\text { Large adenomas }\end{array}$ & $\begin{array}{l}F \\
F \\
F\end{array}$ & $\begin{array}{r}245 \\
69 \\
79\end{array}$ & $\begin{array}{r}35 \cdot 1 \\
20 \cdot 3 \\
8 \cdot 9\end{array}$ & $\begin{array}{l}21 \cdot 6 \\
24 \cdot 6 \\
24 \cdot 1\end{array}$ & $\begin{array}{l}28 \cdot 6 \\
33 \cdot 3 \\
41 \cdot 8\end{array}$ & $\begin{array}{l}14 \cdot 7 \\
21 \cdot 7 \\
25 \cdot 3\end{array}$ & $\mathrm{p}<0.001$ \\
\hline $\begin{array}{l}\text { Population controls } \\
\text { Cancer }\end{array}$ & $\begin{array}{l}\mathbf{F} \\
\mathbf{F}\end{array}$ & $\begin{array}{r}150 \\
62\end{array}$ & $\begin{array}{l}20 \cdot 0 \\
12 \cdot 9\end{array}$ & $\begin{array}{l}23 \cdot 3 \\
25 \cdot 8\end{array}$ & $\begin{array}{l}24 \cdot 7 \\
33 \cdot 9\end{array}$ & $\begin{array}{l}32 \cdot 0 \\
27 \cdot 4\end{array}$ & $\mathrm{p}<0.05$ \\
\hline
\end{tabular}

The groups were similar regarding education standard. As for symptoms that lead to endoscopy, for the adenoma and polyp free groups, the small adenoma and the polyp free groups were comparable in terms of the most severe symptoms that led to colonoscopy; rectal bleeding was a more common symptom in the large adenoma groups (53.4\%) than in the other endoscopy groups (small polyp group: $26 \cdot 0 \%$, polyp free group: $22 \cdot 8 \%$ ). In this area, endoscopy is a widely available procedure and gastroenterologists are directly paid by the 'Sécurite Sociale' (the French national health service). Recruitment for endoscopy was independent of the familial history of cancer, as there is no consensus on the influence of such a history on the risk of colorectal tumours. Colonoscopy had to have at least reached the junction between the sigmoid and the descending colon; in most cases, when it was incomplete, it was completed by a double contrast barium enema. Colonoscopy reached the hepatic flexure at least, in $64.4 \%, 66.2 \%$, and $60.8 \%$ of the large adenoma, small adenoma, and polyp free groups, respectively.

In the adenoma groups, the number of adenomas that had been removed was recorded, as well as the degree of dysplasia using the WHO classification. ${ }^{8}$ Histopathological diagnoses were performed in two laboratories centralising all pathological examinations in the area. Previous collaborative work had ensured a good consensus on the pathological features of colorectal tumours. The presence of a villous component in at least one of the polyps removed was seen in $6.5 \%$ of the small adenoma patients and $39.0 \%$ of the large adenoma patients. The highest degree of dysplasia among the resected adenomas was mild in $76.0 \%$, moderate in $23.4 \%$, and severe in $0.6 \%$ for the small adenoma group. Corresponding values were $32 \cdot 7 \%, 59 \cdot 1 \%$, and $8.2 \%$ in the large adenoma group.

All subjects were interviewed at home about

TABLE II Frequency of a family history of cancer by type of cancer and by study group

\begin{tabular}{|c|c|c|c|c|c|}
\hline \multirow[b]{2}{*}{ Family history of } & \multicolumn{5}{|c|}{$\%$ With a family history of cancer } \\
\hline & $\begin{array}{l}\text { Polyp free } \\
\text { controls } \\
(n=426)\end{array}$ & $\begin{array}{l}\text { Small } \\
\text { adenomas } \\
(n=154)\end{array}$ & $\begin{array}{l}\text { Large } \\
\text { adenomas } \\
(n=208)\end{array}$ & $\begin{array}{l}\text { Cancer } \\
(n=171)\end{array}$ & $\begin{array}{l}\text { Population } \\
\text { controls } \\
(n=309)\end{array}$ \\
\hline $\begin{array}{l}\text { Cancer (any type) } \\
\text { Colorectal cancers } \\
\text { Non-colorectal cancers } \\
\text { Multiple cancers }\end{array}$ & $\begin{array}{r}37 \cdot 3 \\
10 \cdot 6 \\
29 \cdot 3 \\
7 \cdot 0\end{array}$ & $\begin{array}{r}38 \cdot 3 \\
11 \cdot 7 \\
31 \cdot 8 \\
9 \cdot 1\end{array}$ & $\begin{array}{l}41 \cdot 8 \\
18 \cdot 8 \dagger \\
27 \cdot 9 \\
7 \cdot 2\end{array}$ & $\begin{array}{c}45 \cdot 6 \ddagger \\
15 \cdot 8 \ddagger \\
35 \cdot 7 \ddagger \\
9 \cdot 4\end{array}$ & $\begin{array}{r}26 \cdot 9 \\
8 \cdot 1 \\
21 \cdot 7 \\
5 \cdot 8\end{array}$ \\
\hline
\end{tabular}

^Adenoma groups compared with the polyp free controls; cancer group compared with the population controls. Significance of the $\chi^{2}$ test: $p<0 \cdot 01 \dagger ; \neq p<0 \cdot 001$. their personal and familial medical history. The family history of cancers in first degree relatives (parents, siblings, children) was coded as follows: multiple history of cancer corresponded to subjects who had more than one first degree relative with any kind of cancer; FHCRC was defined as at least one first degree relative with a history of colorectal cancer, and family history of other cancers (FHOC) as at least one first degree relative with a history of cancer other than colorectal.

Each adenoma group was compared with the polyp free groups, and the cancer group with the population control group. Distributions were compared with the $\chi^{2}$ test. Relative risks of colorectal tumours according to the family history of cancer were estimated by the odds ratios calculated with an unconditional logistic regression. The statistical significance of each studied variable was tested by the maximum likelihood method. Population attributable risk AR was calculated as proposed by Bruzzi et al..$^{9}$ It can be estimated from regression models, as $\mathrm{AR}=1-\Sigma \rho j / \mathrm{Rj}$ where $\rho j$ is the proportion of cases in the $j$ stratum and $R j$ the relative risk estimate for the corresponding stratum. In the case of a saturated model with several factors, such as, in this study, the model for studying the combined effect of alcohol and tobacco, the summary attributable risk $\mathrm{AR}$ is calculated from $(1-\mathrm{AR})=(1-\mathrm{AR} 1) \times(1-\mathrm{AR} 2)$. Calculations were performed using BMDP $4 \mathrm{~F}$ and $\mathrm{LR}$ software programs. ${ }^{10}$

\section{Results}

\section{Family history of cancer and risk of colorectal adenomas}

Table II gives the frequency of a family history of cancer in each group. The frequency of a positive FHCRC was close to $11 \%$ both in the small adenoma group and in the polyp free group whereas it was $18.8 \%$ in the large adenoma group $(p<0.01)$. There was no significant difference between the three groups regarding FHOC, or family history of multiple cancers.

Age did not modify the frequency of FHCRC in any group. In large adenoma patients it was $17 \cdot 7 \%$ before the age of 60 $(n=79)$ and $19.4 \%$ thereafter $(n=129)$. FHCRC tended to be more common in the case of moderately or severely dysplastic adenomas $(18 \cdot 1 \%, \mathrm{n}=177)$ than in the case of adenomas with only mild dysplasia $(13.5 \%$, $\mathrm{n}=185$ ). Likewise, it was more common when there were at least two adenomas $(19.9 \%$, $\mathrm{n}=146$ ) than when there was only one adenoma $(13.0 \%, \mathrm{n}=216)$. It was also more frequent in case of a purely villous adenoma $(23 \cdot 1 \%, n=13)$ than in the case of a tubulovillous $(15.6 \%, n=77)$ or tubulous adenoma $(15.4 \%, n=272)$. The differences were not statistically significant, however. Small nonsignificant differences were seen according to the degree of completion of the colonoscopy. FHCRC was seen in 10.8 and $10.2 \%$ respectively of the polyp free controls whether or not they reached the hepatic flexure. 
TABLE III Age and sex adjusted relative risk of colorectal tumours according to a family history of colorectal cancers (FHCRC) or of other cancers (FHOC)

\begin{tabular}{|c|c|c|c|}
\hline & \multicolumn{3}{|l|}{ Family history of } \\
\hline & Colorectal cancer & Other cancers & Multiple cancers \\
\hline \multicolumn{4}{|l|}{ Small adenomas $†$} \\
\hline $\begin{array}{l}\text { Unadjusted odds ratio }(95 \% \mathrm{CI}) \ddagger \\
\text { Adjusted odds ratio }(95 \% \mathrm{CI}) \ddagger\end{array}$ & $\begin{array}{l}1.2(0.7 \text { to } 2 \cdot 2) \\
1.2(0.7 \text { to } 2 \cdot 2)\end{array}$ & $\begin{array}{l}1.2(0.8 \text { to } 1.9) \\
1.2(0.8 \text { to } 1.8)\end{array}$ & $1 \cdot 4(0 \cdot 7$ to $2 \cdot 8)$ \\
\hline \multicolumn{4}{|l|}{ Large adenomast } \\
\hline $\begin{array}{l}\text { Unadjusted odds ratio }(95 \% \mathrm{CI}) \ddagger \\
\text { Adjusted odds ratio }(95 \% \mathrm{CI}) \ddagger\end{array}$ & $\begin{array}{l}2 \cdot 1(1.3 \text { to } 3.4)^{\star} \\
2 \cdot 1(1.3 \text { to } 3.4)^{\star \star}\end{array}$ & $\begin{array}{l}0.9(0.6 \text { to } 1.4) \\
0.9(0.6 \text { to } 1.4)\end{array}$ & $1.0(0.5$ to $2 \cdot 0)$ \\
\hline \multicolumn{4}{|l|}{ Cancerst } \\
\hline Adjusted odds ratio $(95 \% \mathrm{CI}) \ddagger$ & $1.9(1.1 \text { to } 3.5)^{\star}$ & $2 \cdot 1(1 \cdot 4 \text { to } 3 \cdot 2)^{\star \star \star}$ & $10(00002)$ \\
\hline
\end{tabular}

${ }^{\star} \mathrm{p}<0.05 ;{ }^{\star \star} \mathrm{p}<0.01 ;{ }^{\star \star}{ }^{\star} \mathrm{p}<0.001$. †Adenoma groups compared with polyp free controls, cancer group compared with population controls. ‡Unadjusted: adjusted only on age and sex; adjusted: adjusted on age, sex, and FHCRC for FHOC, adjusted on age, sex, and FHOC for FHCRC. $\mathrm{CI}=$ confidence intervals.

Corresponding figures were $13 \cdot 7 \%$ and $7 \cdot 7 \%$ for the small adenoma group and $19.4 \%$ and $17 \cdot 6 \%$ for the large adenoma group.

Table III gives the age and sex adjusted odds ratios for colorectal adenomas in relation to family history of cancer. FHCRC multiplied by $2 \cdot 1$ the risk of large adenomas $(p<0 \cdot 01)$, but did not influence the risk of small adenomas. Controlling for symptoms (rectal bleeding versus no rectal bleeding) did not modify the association between FHCRC and large adenomas (OR $2.3 ; 1 \cdot 4-3 \cdot 7$ ). FHOC had no significant effect, whatever the size of the adenoma.

Family history and risk of colorectal cancers Both FHCRC and FHOC were significantly more common in the cancer cases than in the population controls (Table II). A FHCRC was seen in $15.8 \%$ of the cases and $8.1 \%$ of the controls $(p<0.01)$. A FHOC was seen in $35.7 \%$ of the cases and $21.4 \%$ of the controls $(\mathrm{p}<0.001)$. These cancers (FHOC) were mainly other types of digestive cancer $(25.8 \%$ and $31.7 \%$ of the non-colorectal cancers in the case and the control group respectively), cancers of the breast or uterus $(14.5 \%$ and $20.6 \%$ in the case and in the control groups), and lung cancers $(14.5 \%$ and $11.1 \%$ respectively). There was no significant difference of rate of multiple cancers.

In cancer cases, FHCRC was independent of age, and of the stage at diagnosis. It was $14.9 \%$ below age 60 and $16 \cdot 1 \%$ in older patients ( $n=47$ and $n=124$ respectively); it was $15.3 \%$ for Dukes's A and B cancers and $16.7 \%$ for Dukes's C and metastatic tumours.

Table III shows age and sex adjusted odds ratios for colorectal cancer in relation to FHCRC or FHOC. The risk of cancer was multiplied by $2.1 \quad(p<0.05)$ in case of a FHCRC, and by $2.4(p<0.001)$ in case of a FHOC. When including both FHCRC and FHOC in the logistic model adjusted by age and sex, both factors remained independently related to the risk of colorectal cancer.

\section{Population attributable risks}

From the Bruzzi formula, using data from Tables II and III, the proportion of large adenomas that could be attributed to a family history of colorectal cancer was $9 \cdot 8 \%$. For colorectal cancer, the corresponding proportion was $7 \cdot 5 \%$, while the proportion attributable to FHOC was $18 \cdot 7 \%$. Altogether, the proportion of colorectal cancers that could be attributed to a family history of colorectal cancer or of other cancers was calculated as $24 \cdot 8 \%$.

\section{Discussion}

This study brought out two important aspects. The risk of colorectal cancer in subjects with FHCRC was doubled, as was the risk of large adenomas, whereas the risk of small adenomas was not affected. Subjects with a family history of any type of cancer seemed to run the risk of colorectal cancer but not of adenomas.

Possible limitations of our findings must be discussed. These include the discussion of the chosen cut off point for adenoma size, risk of misclassification because of incomplete colonoscopy, and mainly potential selection and recall bias. The $1 \mathrm{~cm}$ cut off point was chosen as it is currently used in analytical studies on adenomas, and corresponds to a true difference in the risk of recurrence and of malignancy. ${ }^{11}$ The relatively high rate of incomplete colonoscopies could result in misclassification of some patients considered as polyp free or with only small adenomas. However, misclassification of cases, unrelated to the variable of interest, results in reducing the effects observed towards absence of effect; the relative risks we saw can therefore be considered minimal estimates. The choice of the control group is another important issue in case control studies. This study was designed as two parallel case control studies to limit selection biases. A community based control group was felt to be the best choice to compare with the cancer group, as it was a random sample of all colorectal cancers arising in the area, recruited with the help of a well established registry of digestive tumours. As for the adenoma patients, it was necessary to compare them to polyp free patients recruited through the same endoscopy units, as patients diagnosed as having adenomas represent only a small sub-sample of all adenoma patients. Indeed, all studies on adenomas are limited to patients who seek medical advice, usually for symptoms unrelated to the presence of adenomas, such as the irritable bowel syndrome. Subjects were obtained from each private and public gastroenterology unit in the area, to increase the external validity of our findings. The validity of data obtained only through an interview may also be questioned. A recent study ${ }^{12}$ showed that people accurately remember the cause of death of their close relatives and that the empirical risks of a subject developing colorectal cancer can be reliably estimated on the basis of the family tree.

An increased risk of colorectal cancer in the case of FHCRC has already been well demonstrated $^{12-17}$ but estimates of the relative risk vary from $1 \cdot 8$ to $8 \cdot 0$. Most studies agree on a prevalence of FHCRC close to $17 \%$, although two studies found a higher ${ }^{13}$ or a lower ${ }^{14}$ figure. The main difference in the studies available resides in the prevalence of FHCRC in the control groups. All studies with an estimated 
relative risk of 2 , like ours, describe a prevalence of between 5 and $10 \%$, whereas those describing a higher relative risk ${ }^{15} 16$ have a low prevalence of FHCRC, $2.0 \%$ and 3.\% respectively. Considering that cumulative risks of colorectal cancer range from 3 to $5 \%$ in Western countries, a minimal prevalence of $6 \%$ can be expected for FHCRC. Therefore, a twofold risk of colorectal cancer in the case of FHCRC is probably close to reality.

The most original aspect of this study was the high prevalence of FHCRC in patients with large adenomas, but not in those with small adenomas only. Three other studies ${ }^{12-14}$ have shown a high frequency of FHCRC in patients with adenomas. They did not attempt to differentiate between small and large adenomas, however, although there is much evidence to suggest that they exhibit dramatically different risks of subsequent colorectal cancer. ${ }^{111819}$ One explanation for familial clustering of colorectal adenomas could be common environmental factors. Little is known, however, about risk factors specific to large adenomas, and in a previous study, we found only alcohol to be a risk factor for large adenomas. ${ }^{7}$ It is often hypothesised that the genetic predisposition to cancer could act at the step of adenoma formation. ${ }^{56}$ Our data, dealing for the first time with this question, suggest that the genetic background to colorectal adenomas does not influence the first, but the second step of the adenoma-carcinoma pathway - that is, adenoma growth. A link between the genetic background and large adenomas could be proposed through liver metabolism. Indeed, there is experimental and epidemiological evidence to suggest that bile acids play an important part in adenoma growth. ${ }^{20}$ Recently published data suggest an interaction between a genetic factor and the bile acids profile. Patients with familial polyposis coli, but also patients with sporadic colorectal cancer, differed from controls in the composition of their biliary bile. ${ }^{21} 22$ Another aspect of differences in liver metabolism between colorectal cancer cases and controls is a higher proportion of cases with a fast acetylator status. ${ }^{23}$ It can be suggested that subjects with this genetic predisposition to colorectal tumours are more sensitive to dietary factors. There is some evidence that the genetic predisposition to colorectal cancer could be transmitted as a low penetrance autosomal dominant trait. ${ }^{56}$ This low penetrance could be explained by a certain proportion of the people prone to colorectal cancer who are not exposed to the aforementioned dietary risk factors.

The second important finding was that a family history of cancer, whatever the type, increased the risk of colorectal cancer but not of colorectal adenomas. Common environmental factors are less likely for cancers of various types than for familial clustering of colorectal cancers. This suggests the existence of a gene or several genes that control for the risk of malignant changes, and are not specific of a particular type of cancer. Such genes, which control for DNA mismatch repair, have recently been described on chromosomes 2 and $3,{ }^{23}$ and involved in hereditary nonpolyposis colorectal cancer syndrome, which is characterised by an increased risk of several types of cancer. Replication errors (RER+ phenotype) have also been identified in cells of sporadic colorectal cancers. ${ }^{24} 25$ but not in adenomas. ${ }^{25}$ Genetic abnormality of this kind would increase the sensitivity to mutagens of actively dividing cells, such as those of promoted adenomas.

In conclusion, this study shows for the first time that two familial risk factors could independently increase the risk of colorectal cancer, one acting at the level of adenoma growth and specifically related to colorectal tumours, and a non-specific factor, which would increase the risk of malignant changes. Patients with both a large adenoma and a family history of cancer are at high risk of colorectal cancer and should be considered as a priority group for prevention studies.

This work was supported by the INSERM (CRE 87-8011). We wish to thank Mrs Lieubray, Mrs Grillet, and Mrs Belghiti who performed the interviews, Drs Bataillon, Bedenne, Carli, Gambert, Garaudet, Hillon, Jacquot, Klepping, Massart, Meny, Riot, Roy, and Villand for their participation, and $\mathrm{Dr} \mathrm{Ph}$ Marteau for his help in revising the manuscript.

1 Groden J, Thliveris A, Samowitz W, Carlson M, Gelbert L, Albertsen $\mathrm{H}$, et al. Identification and characterization of the familial adenomatous polyposis coli gene. Cell 1991; 66: 589-600.

2 Leach FS, Nicolaides NC, Papadopoulos N, Liu B, Jen J, Parsons R, et al. Mutations of a mutS homolog in hereditary non polyposis colorectal cancer. Cell 1993; 75: $1215-25$.

3 Lindblom A, Tannergärd P, Werelius B, Nordenskjöld M. Genetic mapping of a second locus predisposing to hereditary non-polyposis colon cancer. Nature Genetics 1993; 5: 279-82.

4 Fearon ER, Vogelstein B. A genetic model for colorectal tumorigenesis. Cell 1990; 61: 759-67.

5 Burt RW, Cannon-Albright LA, Bishop DT, Skolnick MH. Dominant inheritance of adenomatous colonic polyps and colorectal cancer. N Engl ₹ Med 1985; 312: 1540-4.

6 Cannon-Albright LA, Skolnick MH, Bishop DT, Lee RG, Burt RW. Common inheritance of susceptibility to colonic adenomatous polyp and associated colorectal cancers. N Engl f Med 1988; 319: 533-7.

7 Boutron MC, Faivre J, Dop MC, Quipourt V, Senesse P. Tobacco, alcohol and colorectal tumors: a multistep process. Am 7 Epidemiol 1995; 141: 1038-46.

8 Morson BC, Sobin LH. Histopathological typing of intestinal tumours. Geneva: WHO, 1976.

9 Bruzzi P, Green SB, Byar DP, Brinton LA, Schairer C. Estimating the population attributable risk for multiple Estimating the population attributable risk for multiple
risk factors using case-control data. Am $\mathcal{F}$ Epidemiol 1985; 122: 904-14.

10 Dixon WJ, Brown NB, Engelman L, Frane JW, Mill MA, Jenrich RE, et al. BMDP Statistical Software. Los Angeles: UCLA Press, 1988.

11 Atkin WS, Morson BC, Cuzick J. Long-term risk of colorectal cancer after excision of rectosigmoid adenomas. $N$ Engl $¥$ Med 1992; 326: 658-62.

12 Bonelli L, Martines H, Conio M, Bruzzi P, Aste M. Family history of colorectal cancer as a risk factor for benign and malignant tumours of the large bowel. A case-control malignant tumours of the large bow

13 Stephenson BM, Finan PJ, Gascoyne J, Garbett F, Murday VA, Bishop DT. Frequency of familial colorectal cancer. Br $\mathcal{F}$ Surg 1991; 78: 1162-6.

14 Ponz de Leon M, Antonioli A, Ascari A, Zanghieri G, Sacchetti C. Incidence and familial occurrence of colorectal cancer and polyps in a health-care district of Northern Italy. Cancer 1984; 60: 2848-59.

15 Duncan JL, Kyle J. Family incidence of carcinoma of the colon and rectum in North-East Scotland. Gut 1993; 23: 169-71.

16 Maire P, Morichaud-Beauchant M, Drucker J, Barboteau MA, Barbier J, Matuchansky C. Prevalence familiale du cancer du colon et du rectum: résultats d'une enquète cas-témoin de 3 ans. Gastroenterol Clin Biol 1984; 8: c2-7.

17 Kune GA, June $S$, Watson LF. The role of heredity in the etiology of large bowel cancer: data from the Melbourne Colorectal Cancer Study. World f Surg 1989; 13: 124-31.

18 Lofti AM, Soencer RJ, Ilstrup DM, Melton JL III. Colorectal polyps and the risk of subsequent carcinoma. Colorectal polyps and the risk of
Mayo Clin Proc 1986; 61: 337-43.

19 Grossman S, Milos ML, Tekawa IS, Pewell NP. 
Colonoscopic screening of persons with suspected risk factors for colon cancer: II. Past history of colorectal neoplasms. Gastroenterology 1989; 96: 299-306.

20 Hill MJ. Bile acids and colorectal cancer: hypothesis. Eur Cancer Prev 1991; 1 (suppl 2): 69-72.

21 Spigelman AD, Owen RW, Hill MJ, Phillips RKS. Biliary bile acid profiles in familial adenomatous polyposis. $\mathrm{Br} f$ Surg 1991; 78: 321-5.

22 Tocchi A, Basso L, Costa G, Lepre L, Lotta G, Mazzoni G. Qualitative analysis of bile in patients with colorectal Qualitative analysis of bile in patients with colorecta

23 Kadlubar FF, Butler MA, Kaderlik KR, Chou HC, Lang
NP. Polymorphisms for aromatic amine metabolism in humans: relevance for human carcinogenesis. Environ Health Perspect 1992; 93: 69-74.

24 Lothe RA, Peltomäki P, Meling GI, Aaltonen LA Nyström-Lahti M, Pylkkänen L, et al. Genomic instability in colorectal cancer: relationship to clinicopathological variables and family history. Cancer Res 1993; 53. 5849-52.

25 Young J, Leggett B, Gustafson C, Ward M, Searle J Thomas L, et al. Genomic instability occurs in colorectal carcinomas but not in adenomas. Human Mutations 1993; 2: $351-4$. 